\title{
An interview with Keri Facer
}

In this interview set asks Keri Facer, author of Learning Futures: Education, Technology, and Social Change (2011), about her ideas and what keeps her optimistic about the future. Her book makes a powerful case for reimagining the role of education in response to environmental, social and technological changes. She advocates for schools to be at the centre of "future-building" work in their communities.

\section{Q. What motivated you to write Learning Futures?}

A. Well there's a couple of things really. First, I was just so frustrated by the impoverished ideas of the future that were dominating educational policy and educational discourse, it was either technocentric romanticism or economic instrumentalism, and these are both deeply problematic. I was also very concerned by some of the risks around the inequalities that would be exacerbated by these ideas about the future, so I thought it was quite important to start putting different ideas out there. Second, I'd just headed up the Beyond Current Horizons programme, ${ }^{1}$ but there were things I couldn't say or focus on in that work that I wanted to say. I also wanted to get it out to a wider readership. Writing the book was really about trying to start a conversation about the assumptions that we have about the future in regards to education. I wrote it intentionally for an intelligent readership interested in education, not just for academics. I wrote it in the way that I would like to read books.

As you've alluded, your book opens by challenging "orthodox" views of the future. How have people responded to these ideas?

People interpret the ideas quite differently. There are some people who listen to whatever you say and assume you are saying what they think. For example I have stood up in front of an audience and said "Do not take the

1 http://www.beyondcurrenthorizons.org.uk/ knowledge economy for granted, do not assume that it is just technological change that is going to be shaping our future" and seen a blog written the next day that says "Keri Facer says that the future of education is going to be digital technologies, because we need to prepare everybody for the new knowledge economy". On the other hand there have been quite a few people who've responded very positively, picking up the ideas and trying to explore what they might actually mean in practice. Quite a few teachers and people designing new schools have tried to take some of the ideas in the book and say "Well what would this mean today, what would this mean in schools?" I think it's also been well received by people who've wanted to express their own disquiet with some of the overarching assumptions about the future that they're operating with in education. I think the book has provided quite useful backup for people who've wanted to say "Actually, there is something wrong with the ideas of the future that we're operating with at the moment".

Are there things you would change or add to the book if you were to rewrite it now?

I think there are things I didn't make enough of. I think I could have talked about social and economic inequalities in much more strident terms, although I thought I did at the time. There are still people who don't read that into it. If I were writing it now, I would also probably do a whole separate chapter on the whole environmental and resource issues that we're facing. Particularly because we've got 
such a powerful lobby that is pretending that there are no environmental or resource issues that we need to confront. I think the book touched on those things, and I assumed, because I was writing for intelligent audiences, that people would be aware of it. The problem is that there are so many people who still don't take those issues sufficiently seriously, and haven't thought about their implications for education sufficiently.

\section{Why do you think this is?}

I think there's all sorts of reasons why people don't want to confront some of these issues. They're difficult and they're potentially frightening, and it's much easier if you put them in a box, and pretend they're not there. What we need to do-with our students and our young people as well —is to find a way of having the conversations about some of the challenges that might lie ahead, but also make clear the actions and the steps that we can take. Otherwise, frankly, it's just frightening, and fear isn't useful to anyone. We have to be giving [young people] more opportunities to think and to act than their current school structures do-they will have a maths lesson one minute, and next minute they'll have a lesson on environmental disaster, and the next minute they'll have a lesson on French or something, and there's a huge disconnect between those different experiences. And even when we're discussing these issues with young people it is to often simply "Oh look! Here's global warming, we're looking at 2-3 degree temperature rise, oh here's some recycling you can do." That's completely inadequate, and kids aren't stupid, they're aware that that's inadequate. We need to find ways to have these conversations that aren't just liberal, tokenistic, makeourselves-feel-better-about-it because we've said something. We actually have to turn it into some substantive actions that people can take.

What are some of the things that schools and communities can do to become more intentionally "future building"?

Well, there's practical stuff_-simply thinking carefully about how our schools are using their resourcesthey are employers, they have land and buildings, they have gardens and use energy etcetera. How are these contributing positively to the futures of their communities - environmentally, socially, economically? Are all schools living-wage employers? Are they creating more divisions through their admissions procedures, or more cohesion? Are they stewarding their environment well? This is practical stuff a principal can sit down, think about and act on quickly.

More fundamentally, there's a conversation that has to be had about educational purpose with parents, communities, teachers, and students. You've got to get on the table, what are the assumptions about the future that we are operating with? What are the things that underpin [these assumptions], how might they be changed or disrupted? What steps might you take now to explore other futures that might be possible, that might be latent in the present? A future-building school should be creating space for those conversations. They can happen in personal and social education, they can happen in assemblies, they can happen in after-school activities, they can happen in parent-teacher meetings, they can happen in school governance. Once you have that debate going in the school, this is great. There is then a technical question of how you connect them with your mainstream subject areas. That's a complicated issue. I think John Morgan's work on thinking about curriculum "as if the planet mattered", is a useful example [see Matthewman and Morgan, "Sharpening New Zealand's Future Focus: A Scenaric Stance”, this issue].

What interesting examples have you seen of schools and their communities having those kinds of conversations?

Some of the "sustainable schools" movement are beginning to get there-although I think they often don't address the economic and social justice issues sufficiently. But I'm really interested in the co-operative schools movement. The co-operative tradition in the UK dates back over 150 years, and the co-operative movement internationally has one billion people involved, it's massive! What's interesting about the co-operative movement is that it offers structures that enable debate and collective action. In the last 3 years in the UK, we've seen a growth from pretty much a standing start now to 500 schools that are all officially co-operative schools, running with a co-operative ethos, co-operative governments, curriculum, and pedagogy. Not all of them are working to the extent that you might like, in terms of addressing some of these questions. Some of them have a governance model that enables students, parents, and teachers to come together to have conversations about the core business of schooling, you know, what should curriculum be? What should we be teaching and learning? How should we use our resources? It really embeds in the school a meaningful dialogue about educational purpose and enables teachers then to make real and substantive changes to curriculum, how the school works, who is involved. I think that's really what we need, but you have to start small. You have to start with the tiny steps to building conversations between parents and schools, and children, and communities. This means spending time getting the tricky things like governance and school access right. 
What kinds of knowledge do today's young people need?

I think the critical question is one that Michael Young asks — what counts as powerful knowledge? You can only answer that question if you think carefully about your assumed future, and the whole variety of possibilities that the future might bring. For some situations, it's going to be very traditional "schooled" knowledge, and that's fine. You know, in some situations, you're going to really want to know quadratic equations, because they help you sort out particular engineering problems. In other situations, you're going to want to know about indigenous knowledges, because they help you understand who you are, they also help you produce a different explanation of the world. I was talking with a climate scientist the other day and he was talking about how he uses both advanced mathematics in making sense of satellite data and the historic knowledge and experiences of the people living in the arctic. This just emphasises to me that there isn't ever one sort of knowledge that will prepare you for the future, either traditional disciplinary knowledge, or, alternatively, thinking skills, competencies, or a personalised learning approach. There isn't only one kind of powerful knowledge "for the future", because there is no such "thing" as the future. The future does not exist. You cannot construct a curriculum around a figment of the imagination. So, we need to enable people to learn from, respect and think carefully about which knowledges are useful in which situations, and how they might usefully come together.

What educational ideas, beliefs, practices, or norms do you think we need to let go of in order to be effective future builders?

I think the kind of key assumptions we have to lose is the idea that education is just preparation for university (which assumes that universities are going to be still the same in 15 years' time, and they aren't necessarily) and the idea that education is simply preparation for work, you know, the drive of economic instrumentalism. Neither of those ideas are particularly useful. We need to get into the underlying assumptions that drive that sort of thinking: for example, people want their kids to be happy, healthy, to have a way of earning a living, to be able to form good relationships, and to be able to live in safe communities, you know, these are sort of no-brainer things that people want for their kids. Too often we accept the proxies that people use to stand in for this sort of fundamental aspiration as the goals rather than just the means. We accept it when people say, I want my kids to go to university, without drilling down into, well, why do you want them to go to university? We need to get understand what "going to university" and "getting qualifications" is being used as a proxy for-i.e. living well, being educated and able to shape your future, having a secure life. We need to stop accepting the proxy as the actual purpose of education, and start drilling into what that purpose is.

So-if we assume that the real aspiration is that we want our kids to be able to live well in the future, then one of the questions you want to explore is, what are the best strategies for building communities and societies and worlds that allow children to grow up to be economically viable, resilient people? This means doing things like redefining what "economic resilience" might look like. Too often we just think of "getting jobs", but we may need to think about it in the round. It might involve developing strong networks and communities that can look after and care for our young when we need it. It might be strong communities that are able to support each other when there are moments of difficulty for all of us. What we seem to forget, when we educate to those proxies like "getting a job" or "going to university" is that they are proxies. They're not the real purpose. We should start talking about how we get to that real purpose through education and through other social means.

My favourite chapter of Learning Futures is Chapter 8 , where you move into a storytelling mode and describe an imagined future-building school of 2035 viewed from a parent's perspective. Why did you write it this way?

Well, it's pretty high-risk writing a fictional chapter in the middle of a supposedly serious academic book [laughs]. I wrote it because I didn't want to write a set of predictions. The risk was that I would either end up writing a chapter that said, this will happen, or there would be a set of instructions, this should happen, and neither of those are desirable. You can't say "this should", because people have agency and choice, and need to imagine how they might construct things. You can't say "this will", because that's prediction and is just unsound. I think using fiction, or what a friend of mine would call "rigorous imagining", was the only way to help people occupy a different sort of space in which some of the things we take for granted today have actually changed, while at the same time, leaving readers open to make their own judgements about what the future might be. If you write a story, people can imagine their own stories. There's pretty much nothing in that chapter that doesn't go back to some of the evidence and ideas that underpinned all of the other chapters though. I mean to be honest, you could do a lot of it now. It just requires a little imagination. 
What advice do you have for other people that are interested in using a creative or imaginative process to do that, imagining or thinking about their own idea of a future-building school?

I think the key thing is doing it rigorously. It's not just wishy-washy, it's really trying to push your thinking and use the imagination to do one of two things. One is to emotionally occupy a space, think about what it might be like to be there, to give you a sense of inhabiting a different space, culture, economy, environment. The other is to push it as far as you can go, to say, what if this happened, and then to say, if you pushed it a little bit further and a little bit further and a little bit further, what would it actually be like? There's a lot of preparation I think that should go into creative imagining, it's not just, let's sit down and invent something. You have to do all the other stuff first.

\section{Are you optimistic about the future?}

I oscillate, like everybody else. What keeps me optimistic are old-fashioned words like beauty, wonder, curiosity. I mean if you actually stop and look at the world, it's amazing. That's a resource for feeling optimistic. Novelty happens, and that's not just blind optimism that something will work out, it's actually true; new stuff happens. If we create opportunities for novelty, we might find ways of working our way out of old problems. So, yeah, that, and the ability to self-organise. What keeps me optimistic is when I see the emergence of new coalitions and groups, who aren't stupid, and who are very clear about what we're up against, in terms of constructing seriously better societies. There are groups now, starting to organise in different ways. I do think actually the young people at the moment, in their early 2os, are more than aware of the failures of our current system, both economically and environmentally, and are discovering and inventing new ways of living-although that doesn't mean it should be their responsibility alone to sort this out. I think if we can find ways of building allegiances and coalitions between them and those older people who have other experience and are in other positions of seniority and power, then I think things could start to get really interesting. But it's not about just waiting for the next generation to say this stuff.

Yeah, that's right. Imagine the burden of feeling that they're just there to sort out all the problems that we've created.

Absolutely not! No! We've all got responsibility for this, it's just that some of these young people have got some really fascinating, creative ideas, and you know, working with them is massively invigorating and exciting.
What are you currently working on or thinking about?

One thing I'm doing is a project called "80 by I8", which is, at its simplest, just a list of 80 things that young people might do in the city (of Bristol) before they're I8 years old (www.8obyi8.org.uk). It's a simple idea, but behind it is a desire to mobilise all the resources in the city that might enable people to adapt to all sorts of possible futures. It's about making visible the skills and expertise and resource that there is in communities outside schools. The other thing that it's doing is to try to support young people to feel that they can inhabit and participate in their city, that they have a right to that sort of space. We've done a massive consultation, we've had 6oo-odd ideas across the city, around what these experiences might be. It's anything from running a campaign to talk to the mayor, to doing bio-blitzes in your local area, to meeting people who've got different sorts of expertise. We launched the website in November, and we're working with a group of young people to research how the project reframes their sense of how they occupy the city, and their sense of how they might act, to influence and change their future. This project is also about recognising that schools can't do it all, that we have to just stop asking teachers and schools to "fix everything". If we're interested in enabling young people to create and inhabit futures that they want, we need to mobilise cities, communities, and institutions beyond schools to take some more responsibility for this. This project, at its simplest, is just a list and a website, but underpinning it is a much more challenging idea about building collective responsibility for young peoples' care, education, and futures.

That's where my thinking has gone since Learning Futures. It's about finding spaces to act, and you can act where you stand, and you know, I live in Bristol, I work in Bristol, so the question is how do I support that city to respond to some of the issues that I've raised in the book?

\section{Reference}

Facer, K. (201I). Learning futures: Education, technology and social change. Oxford, UK: Routledge.

Keri Facer is Professor of Educational and Social Futures at the University of Bristol. 